\title{
Cycling Injury Risk in London: Impacts of Road Characteristics and Infrastructure
}

\author{
Thomas Adams ${ }^{1}$, Rachel Aldred ${ }^{2}$ (D) ${ }^{a}$ \\ ${ }^{1}$ Transport for London, 2 University of Westminster \\ Keywords: road characteristics, risk, cycling, infrastructure, injury, route environment \\ 10.32866/001c.18226
}

\section{Findings}

This study of cycling injury risk in London examines impacts of road characteristics and environment, including different types of cycling infrastructure. It controlled for exposure by using a case-crossover method alongside an algorithm developed by Transport for London to predict cyclist routes. When compared to no infrastructure, this study found that protected cycle infrastructure reduced odds of injury by $40-65 \%$ in the morning commute, whereas advisory lanes increased injury odds by $34 \%$. Junctions were found to increase injury odds threefold; higher pedestrian density also increased injury odds. This study supports growing evidence of a 'safety in numbers' effect.

\section{Research Questions}

Road safety interventions have traditionally been prioritised by looking at absolute number of casualties at different locations. Whilst this helps practitioners identify dangerous locations, it will not capture the relative risk per user of different types of infrastructure or route environment.

To assess how characteristics of the route environment affect injury risk for each individual road user, we need to control for exposure (Vandenbulcke, Thomas, and Int Panis 2014; Vanparijs et al. 2015). Epidemiological methods offer ways of doing this. Case-control studies control for exposure by comparing aggregate injury locations to aggregate control locations, with control locations selected from modelled or measured flow data (Miller et al. 2017; Aldred et al. 2018; Meuleners et al. 2019).

By contrast, in case-crossover studies each person serves as their own control, reducing intrapersonal confounding. Control points are selected from a person's route prior to injury, as in Teschke et al. (2012). This study uses a similar method, however, using a cycling route prediction algorithm to generate cyclist routes rather than recall. 


\section{Methods and Data}

Britain's database for police-reported traffic incidents, Stats19, was used to identify cycle injury locations, with casualty home postcode data provided via Transport for London (TfL). Between 2016-2018, 13,700 cycling injuries were reported to police in London. After removing non-London residents and incorrect home postcodes, 11,936 injuries remained.

As we only had home postcode data rather than journey origins, we could only use injuries sustained where a person's home was likely the starting point. For the purposes of routing, their trip needed to be for utility purposes (A to B; i.e. not a weekend leisure ride which might not follow typical utility routing patterns). Morning commuter travel fits both requirements. Therefore, only collisions occurring between 7-10am on weekdays and involving people over 16 were used. This left a total of 2,876 injury points, most of which $(86.7 \%$, or 2,494 ) were slight injuries. 375 were serious and 7 were fatal.

Routes were predicted between home and injury locations on TfL's Cynemon network (which contains all roads and other routes that can legally be cycled) using the Network Analyst tool in ArcGIS. The route prediction tool was programmed to use Cynemon generalised costs for commuters, which places route directness above other factors such as infrastructure and traffic volumes. Cynemon is a cycling assignment model which has primarily been developed to support appraisal of cycling interventions and formation of cycling policy. As such, Cynemon can estimate cyclist routes, flows and journey times.

A control point was introduced for each $3 \mathrm{~km}$ of a cyclist's route, i.e. 1 point for routes under $3 \mathrm{~km}, 2$ points for routes $3-6 \mathrm{~km}$. This method resulted in 5,754 control points, i.e. almost double the number of injury points - which was the target. $80 \%$ of control points were for routes under $12 \mathrm{~km}$ ( $67 \%$ for under $9 \mathrm{~km}$ ). Control points were then selected at random points along the route by using the Random Point Generator tool in ArcGIS. Figure 1 shows the location of these points across Greater London.

Table 1 shows route environment datasets used and sources. Figure 2 illustrates cycling infrastructure in London, taken from the TfL Cycle Infrastructure Database, separated into different types of infrastructure, and Figure 3 provides a composite image of different facility types.

The cycling flow data uses 2016 AM peak hour (08:00-09:00) link flows from Cynemon, which have been calibrated and validated using observed counts. Aggregate temporal and seasonal factors from Strava data were applied to the Cynemon flows to increase precision and better align with the injury data. Temporal factors derived from London Travel Demand Survey (LTDS) data were applied to the pedestrian and traffic flow data. Traffic speed data was obtained from Trafficmaster via DfT: this uses data from GPS-enabled vehicles to generate average flows at peak and off-peak times. 


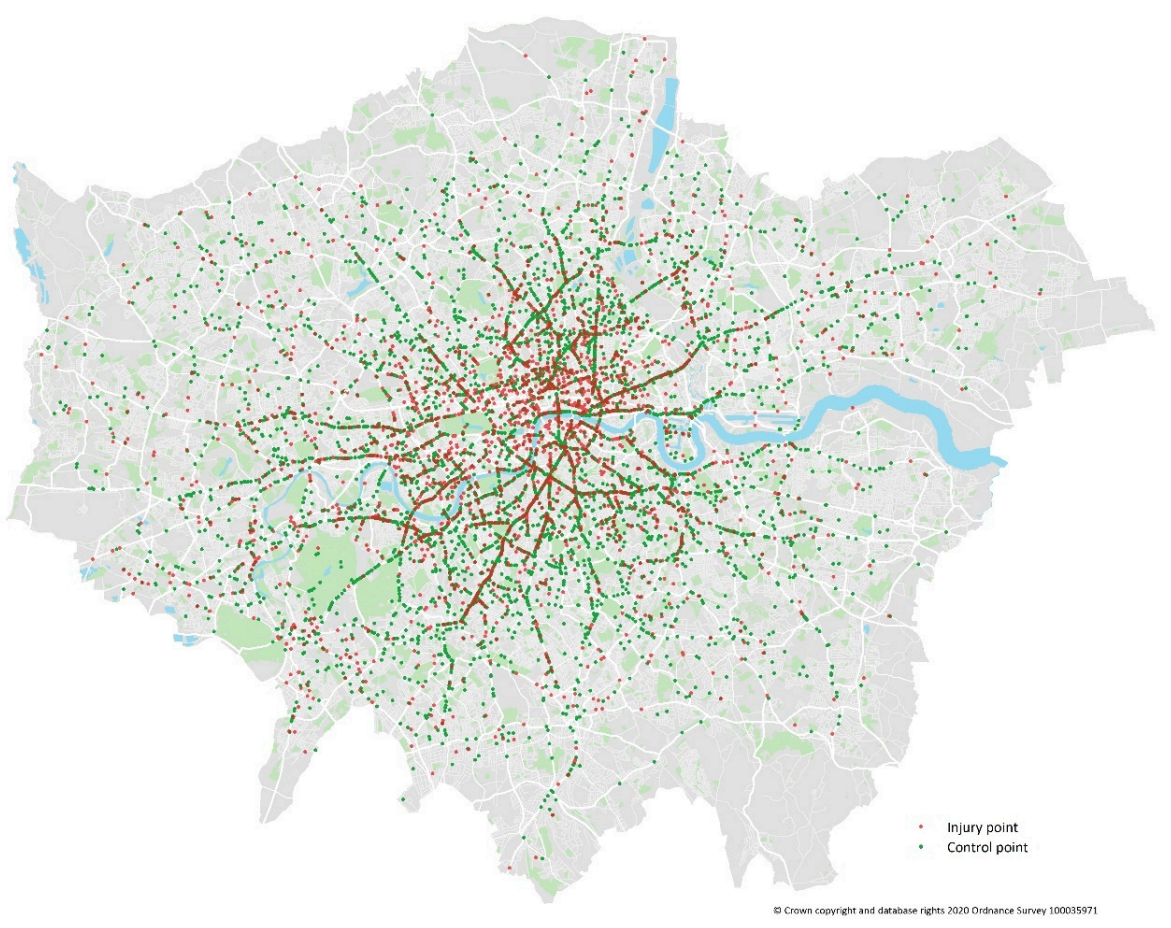

Figure 1: Control and injury points

Table 1: Data sources

\begin{tabular}{|c|c|c|}
\hline Variable & Categories & Dataset (source) \\
\hline Area & Central/Inner/Outer London & Greater London Authority boundary data \\
\hline Road type & 4 classes & ITN network (Ordnance Survey) \\
\hline Intersection & yes/no & ITN network (Ordnance Survey) \\
\hline Speed limit & $20 \mathrm{mph} />20 \mathrm{mph}$ & Digital speed limit map (TfL) \\
\hline Bus lane & yes/no & Bus lane database (TfL) \\
\hline Bus stop & yes/no & Bus stop database (TfL) \\
\hline Speed (mph) & Log transformed morning peak speeds & Trafficmaster (DfT) \\
\hline $\begin{array}{l}\text { Cycle infrastructure: } \\
\text { mandatory cycle lane, } \\
\text { advisory cycle lane, on/off } \\
\text { carriageway, partially or } \\
\text { light kerb-separated cycle } \\
\text { lane/track, kerb-separated } \\
\text { cycle lane/track, stepped } \\
\text { cycle lane/track }\end{array}$ & yes/no & Cycle Infrastructure Database (TfL) \\
\hline Cycle flow (per hour) & Log transformed flows & Cynemon (TfL) \\
\hline Traffic flow (per hour) & Log transformed flows & Highway Assignment Model (TfL) \\
\hline $\begin{array}{l}\text { Pedestrian density } \\
\text { (metres walked per square } \\
\text { metre, per hour) }\end{array}$ & Log transformed pedestrian density & LTDS (TfL) \\
\hline
\end{tabular}




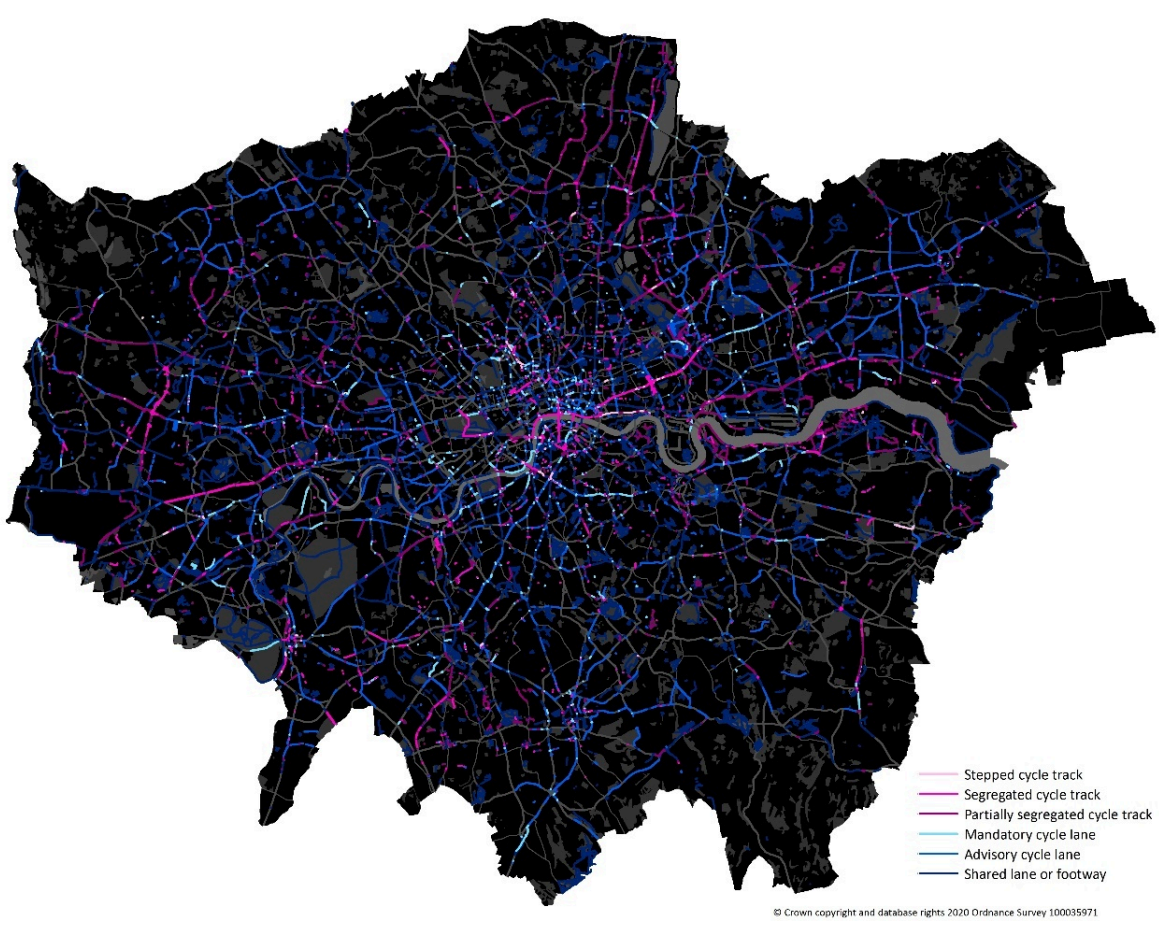

Figure 2: Cycle infrastructure in London

Kerb separated cycle lane/track Cycle lane or track separated by a continuous or near-continuous physical upstand along links (usually verges or kerbed segregating islands)

Stepped cycle lane/track

Vertically separated cycle tracks at an intermediate level between the footway and main carriageway, with or without a buffer

Light separated cycle lane/track A facility separated and protected by intermittently placed objects. These generally include formal, mandatory lane markings.

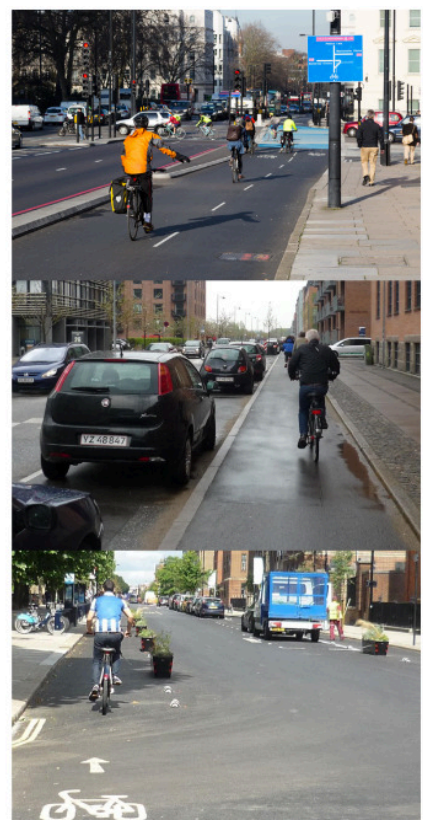

Mandatory cycle lane

A marked lane for exclusive use of cyclists during the advertised hours of operation. It is an offence for other vehicles to enter, unless they are exempted. Separate parking restrictions are needed in order for them to be fully effective.

Advisory cycle lane

An area intended for, but not legally restricted to, cyclists' use. Other vehicles are permitted to enter or cross it.

\section{Shared bus lane}

Cyclists may use the full width of the bus lane during and beyond its hours of operation. Applies to nearside, with-flow bus lanes, and should extend to contraflow and offside types.

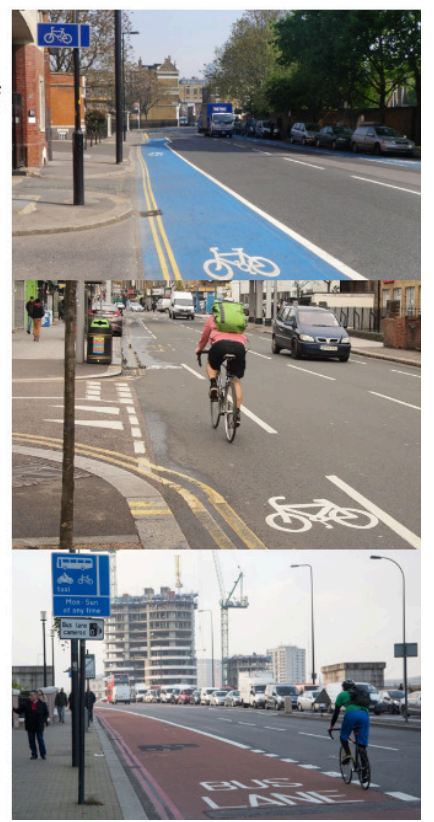

Figure 3: types of cycle infrastructure (source: London Cycle Design Standards)

Road classes were 'A', 'B', 'C' and 'Other'. A roads are primary roads, which include TfL-managed 'red routes', carrying up to 30\% of London's traffic despite only making up 5\% of roads. $\mathrm{B}$ roads are secondary roads, while $\mathrm{C}$ roads tend to connect local roads with $\mathrm{A}$ or $\mathrm{B}$ roads, and 'Other' roads include residential and private roads. 
We performed statistical analysis using similar methodology to Aldred et al. (2018), with binary logistic regression modelling to predict whether a location was an injury or control point. Coefficients (odds ratios) were produced for each variable after controlling for other factors. This indicated whether the variable increased or decreased cycling injury odds and a corresponding significance level (we chose $\mathrm{p}<0.05$ as our threshold). All analysis was undertaken in the statistical package $\mathrm{R}$ (https://www.r-project.org/) and the mixed-effects models were fitted using the 'glmer' function (https://www.rdocumentation.org/packages/lme4/versions/1.1-25/topics/ glmer).

\section{Findings}

Table 2 provides descriptive statistics for route environment characteristics included in the final model, alongside the proportion of points for each characteristic that represent injury sites. Across all points, this proportion is $33.3 \%$, so any value higher than this means an over-representation of injury points for that variable category.

Coefficients related to whether a point was in Inner, Outer, or Central London do not reflect differences in the 'real' risks in each area. Apparent higher risk in Inner and Central areas is an artefact of the method as control points, by definition, lie closer to home than work. Instead, we included this variable to control for possible differences between these areas not included in the table below.

Table 3 presents the results of the two models, alongside univariate odds ratios. Model 1 controlled for road characteristics whilst model 2 also controlled for road user flows (other cyclists, pedestrians, motor traffic). Variables for which $\mathrm{p}=>0.1$ were removed before re-running the models, which made no substantive difference to results.

Cycling at intersections increases injury odds threefold. This is in line with literature on intersections (e.g. Quddus 2008; Harris et al. 2013) and the odds ratio is similar to Aldred et al's London study (2018). B roads were relatively risky compared both to residential streets and $\mathrm{A}$ roads. These findings differ from Teschke et al. (2012) and Aldred et al. (2018).

Kerb separated cycle infrastructure reduced injury odds substantially; by $40 \%$ compared to no infrastructure. Stepped tracks were even more protective, reducing injury odds by $65 \%$, albeit with large confidence intervals due to low numbers (0.15-0.85, CI 95\%). These findings are in line with Teschke et al. (2012) and in London, Li, Graham, and Liu (2017). By contrast, painted cycle lanes did not reduce injury. Mandatory painted lanes did not lead to any risk reduction and advisory lanes (which motor vehicles are legally permitted to enter) increased injury odds by over $30 \%$. 
Table 2: Descriptive statistics, route environment characteristics

\begin{tabular}{|c|c|c|c|c|}
\hline Variable & Categories & Injury & Control & $\%$ Injury points \\
\hline \multirow[t]{3}{*}{ Area } & Central & 777 & 975 & $44.3 \%$ \\
\hline & Inner & 1298 & 2762 & $32.0 \%$ \\
\hline & Outer & 801 & 2017 & $28.4 \%$ \\
\hline \multirow[t]{4}{*}{ Road type } & A Road & 1750 & 3788 & $31.6 \%$ \\
\hline & B Road & 320 & 329 & $49.3 \%$ \\
\hline & C Road & 303 & 672 & $31.1 \%$ \\
\hline & Other & 503 & 965 & $34.3 \%$ \\
\hline \multirow[t]{2}{*}{ Intersection } & No & 544 & 2471 & $18.0 \%$ \\
\hline & Yes & 2332 & 3283 & $41.5 \%$ \\
\hline \multirow[t]{2}{*}{ 20mph limit } & No & 1707 & 3536 & $32.6 \%$ \\
\hline & Yes & 1169 & 2218 & $34.5 \%$ \\
\hline \multirow[t]{2}{*}{ Bus lane } & No & 2341 & 4332 & $35.1 \%$ \\
\hline & Yes & 535 & 1422 & $27.3 \%$ \\
\hline \multirow[t]{2}{*}{ Bus stop } & No & 2745 & 5186 & $34.6 \%$ \\
\hline & Yes & 131 & 568 & $18.7 \%$ \\
\hline \multirow[t]{4}{*}{ Speed (miles per hour) } & $0-10$ & 716 & 1062 & $40.3 \%$ \\
\hline & $10-20$ & 1986 & 4152 & $32.4 \%$ \\
\hline & $20-30$ & 164 & 491 & $25.0 \%$ \\
\hline & $30-40$ & 10 & 49 & $16.9 \%$ \\
\hline \multirow[t]{2}{*}{ Kerb-separated cycle lane / track } & No & 2797 & 5505 & $33.7 \%$ \\
\hline & Yes & 79 & 249 & $24.1 \%$ \\
\hline \multirow[t]{2}{*}{ Partially or light separated cycle lane / track } & No & 2794 & 5556 & $33.5 \%$ \\
\hline & Yes & 82 & 198 & $29.3 \%$ \\
\hline \multirow[t]{2}{*}{ Stepped cycle lane / track } & No & 2869 & 5710 & $33.4 \%$ \\
\hline & Yes & 7 & 44 & $13.7 \%$ \\
\hline \multirow[t]{2}{*}{ Mandatory cycle lane } & No & 2784 & 5544 & $33.4 \%$ \\
\hline & Yes & 92 & 210 & $30.5 \%$ \\
\hline \multirow[t]{2}{*}{ Advisory cycle lane } & No & 2294 & 4825 & $32.2 \%$ \\
\hline & Yes & 582 & 929 & $38.5 \%$ \\
\hline \multirow[t]{4}{*}{ Cycle flow (cyclists per hour) } & $0-100$ & 2081 & 3859 & $35.0 \%$ \\
\hline & $100-250$ & 611 & 1370 & $30.8 \%$ \\
\hline & $250-500$ & 169 & 456 & $27.0 \%$ \\
\hline & $>500$ & 15 & 69 & $17.9 \%$ \\
\hline \multirow[t]{5}{*}{ Traffic flow (motor vehicles per hour) } & $0-250$ & 654 & 1300 & $33.5 \%$ \\
\hline & $250-500$ & 998 & 2003 & $33.3 \%$ \\
\hline & $500-750$ & 574 & 1160 & $33.1 \%$ \\
\hline & $750-1000$ & 334 & 620 & $35.0 \%$ \\
\hline & $>1000$ & 316 & 671 & $32.0 \%$ \\
\hline \multirow[t]{4}{*}{ Pedestrian density (metres walked per square metre, per hour) } & $0-3$ & 1990 & 4273 & $31.8 \%$ \\
\hline & $3-6$ & 528 & 974 & $35.2 \%$ \\
\hline & 6-9 & 173 & 271 & $39.0 \%$ \\
\hline & $9-12$ & 76 & 112 & $40.4 \%$ \\
\hline
\end{tabular}




\begin{tabular}{|l|l|l|l|l|}
\hline Variable & Categories & Injury & Control & \% Injury points \\
\hline & $>12$ & 109 & 124 & $46.8 \%$ \\
\hline All points & & 2876 & 5754 & $33.3 \%$ \\
\hline
\end{tabular}

Table 3: Predictors of cycling injury in London when commuting in the morning

\begin{tabular}{|c|c|c|c|c|}
\hline Variable & Categories & $\begin{array}{l}\text { Univariate } \\
\text { OR }\end{array}$ & $\begin{array}{l}\text { Model } 1 \text { OR }(95 \% \\
\mathrm{Cl})\end{array}$ & $\begin{array}{l}\text { Model } 2 \text { OR (95\% } \\
\text { Cl) }\end{array}$ \\
\hline \multirow[t]{3}{*}{ Region } & Central & 1.00 & 1.00 & 1.00 \\
\hline & Inner & 0.59 & $0.62(0.55,0.71)^{* * *}$ & $0.57(0.50,0.65)^{* * *}$ \\
\hline & Outer & 0.50 & $0.54(0.47,0.63)^{* * *}$ & $0.43(0.37,0.51)^{* * *}$ \\
\hline \multirow[t]{4}{*}{ Road type } & A Road & 1.00 & 1.00 & 1.00 \\
\hline & B Road & 2.11 & $2.14(1.79,2,55)^{* * *}$ & $1.91(1.59,2.30)^{* * *}$ \\
\hline & Croad & 0.98 & $1.10(0.94,1.29)$ & $1.01(0.85,1.20)$ \\
\hline & Other & 1.13 & $1.30(1.13,1.49)^{* * *}$ & $0.95(0.79,1.13)$ \\
\hline \multirow[t]{2}{*}{ Intersection } & No & 1.00 & 1.00 & 1.00 \\
\hline & Yes & 3.23 & $3.02(2.70,3.37)^{* * *}$ & $2.96(2.65,3.31)^{* * *}$ \\
\hline \multirow[t]{2}{*}{ Bus Lane } & No & 1.00 & 1.00 & 1.00 \\
\hline & Yes & 1.09 & $0.70(0.62,0.80)^{* * *}$ & $0.77(0.67,0.87)^{* * *}$ \\
\hline \multirow[t]{2}{*}{ Bus Stop } & No & 1.00 & 1.00 & 1.00 \\
\hline & Yes & 0.70 & $0.52(0.42,0.64)^{* * *}$ & $0.53(0.43,0.65)^{* * *}$ \\
\hline \multirow{2}{*}{$\begin{array}{l}\text { Kerb separated cycle } \\
\text { track }\end{array}$} & No & 1.00 & 1.00 & 1.00 \\
\hline & Yes & 0.62 & $0.54(0.41,0.72)^{* * *}$ & $0.60(0.45,0.80)^{* * *}$ \\
\hline \multirow[t]{2}{*}{ Stepped cycle track } & No & 1.00 & 1.00 & 1.00 \\
\hline & Yes & 0.82 & $0.29(0.12,0.70)^{* *}$ & $0.35(0.15,0.85)^{*}$ \\
\hline \multirow[t]{2}{*}{ Advisory cycle lane } & No & 1.00 & 1.00 & 1.00 \\
\hline & Yes & 1.32 & $1.21(1.06,1.37)^{* *}$ & $1.34(1.18,1.52)^{* * *}$ \\
\hline Traffic speed & $\begin{array}{l}\text { Change per } 1 \log _{2} \\
\text { increase }\end{array}$ & - & $0.75(0.67,0.82)^{* * *}$ & $0.73(0.66,0.81)^{* * *}$ \\
\hline Cycle flow & $\begin{array}{l}\text { Change per } 1 \log _{2} \\
\text { increase }\end{array}$ & - & - & $0.87(0.84,0.90)^{* * *}$ \\
\hline Pedestrian density & $\begin{array}{l}\text { Change per } 1 \log _{2} \\
\text { increase }\end{array}$ & - & - & $1.06(1.01,1.12)^{*}$ \\
\hline Traffic flow & $\begin{array}{l}\text { Change per } 1 \log _{2} \\
\text { increase }\end{array}$ & - & - & $1.04(0.99,1.09)^{\prime}$ \\
\hline
\end{tabular}

${ }^{* * *} p<0.001,{ }^{* *} p<0.01,{ }^{*} p<0.05,{ }^{\prime} p<0.1$

Bus lanes reduced injury odds, although less than protected cycle infrastructure. Bus stops were also, surprisingly, associated with reduced risk. Perhaps they provide a respite from parked cars, which increase risk (Teschke et al. 2012) but are not included in this study.

There is evidence of a 'safety in numbers' effect as an increase in cycle flow reduced injury odds (e.g. Jacobsen 2003; Marques and Hernández-Herrador 2017; Aldred et al. 2018). The study suggests that a doubling of cyclists in the morning commute reduces cycling injury odds by $13 \%$. 
Higher pedestrian density and traffic volume increased risk, although the latter was only borderline significant. A doubling in pedestrian density increased cycling injury odds by $6 \%$. This finding reflects the increased risk of busy high streets, town centres or business hubs.

Counterintuitively, risk decreased as speed increased. When looking at the absolute numbers it appears that roads with speeds less than $10 \mathrm{mph}$ are more dangerous, indicating congestion could increase risk. However, an increase in speed is likely to increase severity of a given injury (Elvik 2013).

In conclusion, cycle infrastructure on main roads and junctions must be protected (kerb separated or stepped tracks, rather than painted lanes), particularly when there is high traffic and/or pedestrian activity.

\section{Acknowledgements}

A special gratitude goes to Transport for London and the Strategic Analysis department, as this study would not have been possible without its data and support. University College London provided a platform for this research which is also appreciated. 


\section{REFERENCES}

Aldred, Rachel, Anna Goodman, John Gulliver, and James Woodcock. 2018. "Cycling Injury Risk in London: A Case-Control Study Exploring the Impact of Cycle Volumes, Motor Vehicle Volumes, and Road Characteristics Including Speed Limits.” Accident Analysis E Prevention 117 (August): 75-84. https://doi.org/10.1016/j.aap.2018.03.003.

Elvik, Rune. 2013. "A Re-Parameterisation of the Power Model of the Relationship between the Speed of Traffic and the Number of Accidents and Accident Victims." Accident Analysis Ev Prevention 50 (January): 854-60. https://doi.org/10.1016/j.aap.2012.07.012.

Harris, M Anne, Conor C O Reynolds, Meghan Winters, Peter A Cripton, Hui Shen, Mary L Chipman, Michael D Cusimano, et al. 2013. "Comparing the Effects of Infrastructure on Bicycling Injury at Intersections and Non-Intersections Using a Case-Crossover Design.” Injury Prevention 19 (5): 303-10. https://doi.org/10.1136/injuryprev-2012-040561.

Jacobsen, P L. 2003. "Safety in Numbers: More Walkers and Bicyclists, Safer Walking and Bicycling." Injury Prevention: Journal of the International Society for Child and Adolescent Injury Prevention 9 (3): 205-9. https://doi.org/10.1136/ip.9.3.205.

Li, Haojie, Daniel J. Graham, and Pan Liu. 2017. "Safety Effects of the London Cycle Superhighways on Cycle Collisions." Accident Analysis E゚ Prevention 99 (Pt A) (February): 90-101. https://doi.org/10.1016/j.aap.2016.11.016.

Marques, R., and V. Hernández-Herrador. 2017. "On the Effect of Networks of Cycle-Tracks on the Risk of Cycling. The Case of Seville.” Accident Analysis E̊ Prevention 102: 181-90.

Meuleners, Lynn B., Mark Stevenson, Michelle Fraser, Jennie Oxley, Geoffrey Rose, and Marilyn Johnson. 2019. "Safer Cycling and the Urban Road Environment: A Case Control Study." Accident Analysis $6^{2}$ Prevention 129 (August): 342-49. https://doi.org/10.1016/j.aap.2019.05.032.

Miller, Philip D., Denise Kendrick, Carol Coupland, and Frank Coffey. 2017. "Use of Conspicuity Aids by Cyclists and Risk of Crashes Involving Other Road Users: Population Based Case-Control Study." Journal of Transport छ Health 7 (December): 64-74. https://doi.org/10.1016/ j.jth.2017.03.008.

Quddus, Mohammed A. 2008. "Modelling Area-Wide Count Outcomes with Spatial Correlation and Heterogeneity: An Analysis of London Crash Data.” Accident Analysis Ev Prevention 40 (4): 1486-97. https://doi.org/10.1016/j.aap.2008.03.009.

Teschke, Kay, M. Anne Harris, Conor C. O. Reynolds, Meghan Winters, Shelina Babul, Mary Chipman, Michael D. Cusimano, et al. 2012. "Route Infrastructure and the Risk of Injuries to Bicyclists: A Case-Crossover Study.” American Journal of Public Health 102 (12): 2336-43. https://doi.org/10.2105/ajph.2012.300762.

Vandenbulcke, Grégory, Isabelle Thomas, and Luc Int Panis. 2014. "Predicting Cycling Accident Risk in Brussels: A Spatial Case-Control Approach.” Accident Analysis E̊ Prevention 62 (January): 341-57. https://doi.org/10.1016/j.aap.2013.07.001.

Vanparijs, Jef, Luc Int Panis, Romain Meeusen, and Bas de Geus. 2015. "Exposure Measurement in Bicycle Safety Analysis: A Review of the Literature.” Accident Analysis Ev Prevention 84 (November): 9-19. https://doi.org/10.1016/j.aap.2015.08.007. 